\title{
Short-term post-mortality scavenging and longer term recovery after anoxia in the northern Adriatic Sea
}

\author{
M. Blasnig ${ }^{1}$, B. Riedel ${ }^{1}$, L. Schiemer ${ }^{1}$, M. Zuschin ${ }^{2}$, and M. Stachowitsch ${ }^{1}$ \\ ${ }^{1}$ University of Vienna, Department of Limnology and Bio-Oceanography, Austria \\ ${ }^{2}$ University of Vienna, Department of Palaeontology, Austria
}

Correspondence to: M. Stachowitsch (stachom5@univie.ac.at)

Received: 2 January 2013 - Published in Biogeosciences Discuss.: 7 March 2013

Revised: 4 October 2013 - Accepted: 23 October 2013 - Published: 26 November 2013

\begin{abstract}
The northern Adriatic Sea is one of nearly 500 areas worldwide suffering widespread mortalities due to anoxia. The present study documents post-anoxia macrofauna dynamics after experimentally inducing small-scale anoxia in $24 \mathrm{~m}$ depth $(2$ plots, each $50 \mathrm{~cm} \times 50 \mathrm{~cm})$. Timelapse camera deployments examined short-term scavenging of the moribund and dead organisms (multi-species clumps consisting of sponges and ascidians) over two 3-day periods (August 2009: $71.5 \mathrm{~h}$, September 2009: 67.5 h). Longer term recovery (days to $2 \mathrm{yr}$ ) in the same two plots was examined with an independent photo series. Scavengers arrived quickly and in a distinct sequence: demersal (Gobius niger, Serranus hepatus) and benthopelagic fishes (Diplodus vulgaris, Pagellus erythrinus), followed by hermit crabs (Paguristes eremita, showing a clear day/night rhythm in presence) and gastropods (Hexaplex trunculus). This sequence is attributed to the relative speeds and densities of the organisms. The sessile fauna was largely removed or consumed within seven (August plot) and 13 (September plot) days after anoxia, confirming our first hypothesis that decaying organisms are quickly utilised. The scavengers remained in dense aggregations (e.g. up to 33 P. eremita individuals at one time) as long as dead organisms were available. No recovery of sessile macroepibenthos macroepibenthos occurred in the experimental plots one and two years after anoxia, undermining our second hypothesis that small denuded areas are more rapidly recolonised. This study underlines the sensitivity of this soft-bottom community and supports calls for reducing additional anthropogenic disturbances such as fishing practices that further impede recolonisation and threaten benthic community structure and function over the long term.
\end{abstract}

\section{Introduction}

Dayton et al. (1995) established that coastal marine ecosystems are the world's most endangered habitats, and the Mediterranean is no exception, with documented impacts on biodiversity (Danovaro and Pusceddu, 2007; Coll et al., 2010). One major disturbance, coastal hypoxia and anoxia, has been exacerbated by eutrophication. No other environmental variable than dissolved oxygen has changed in shallow coastal seas and estuaries so drastically in such a short time (Diaz and Rosenberg, 1995). Hypoxia adversely affects the community structure and trophodynamics of marine ecosystems (Gray et al., 2002), for example by eliminating sensitive species and promoting more tolerant species (Wu, 2002).

The northern Adriatic is one of nearly 500 eutrophicationassociated dead zones worldwide, with a global area of more than $245,000 \mathrm{~km}^{2}$ (Diaz and Rosenberg, 2008). It combines many of the features known to promote late summer hypoxia and anoxia (shallow depth, soft sediments, semi-enclosed water body, stratification, high riverine input, high productivity, long water-residence time; Stachowitsch and Avcin, 1988; Malej, 1995; Stachowitsch, 1991). Combined with anthropogenic eutrophication and massive marine snow events, the northern Adriatic Sea is a sensitive ecosystem (Stachowitsch, 1986) and also among the most heavily exploited and degraded seas worldwide (Lotze et al., 2011a). Bottom-water oxygen content has decreased from the mid-20th century (Justic, 1991) until the early 1990s, associated with extensive mortalities of epibenthic communities (Fedra et al., 1976; Stachowitsch, 1991; Hrs-Brenko et al., 1994). 
Fedra et al. (1976) named the wide-ranging community studied here the Ophiothrix-Reniera-Microcosmus (ORM) community based on the dominant brittle stars Ophiothrix quinquemaculata (Delle Chiaje, 1828), sponges Reniera spp., and ascidians Microcosmus spp. It is largely composed of suspension-feeders aggregated into so-called multispecies clumps or bioherms (Zuschin and Stachowitsch, 2009). Filter- and suspension feeder communities here are an important stabilizing compartment that removes enormous amounts of suspended material from the waterbody (Ott and Fedra, 1977). Such communities have been termed a natural eutrophication control (Officer et al., 1982) and thus provide crucial ecological goods and services.

Damage to or loss of such communities has ecosystemwide implications. During hypoxia and anoxia, the benthic organisms in the ORM community show a distinct sequence of behaviours and mortalities. This has been documented in situ during larger-scale anoxic episodes (Stachowitsch, 1984) and has been confirmed and analysed in great detail experimentally using an underwater chamber $\left(0.25 \mathrm{~m}^{2}\right)$ on a small scale on the seafloor in $24 \mathrm{~m}$ water depth. These behaviours include, for example, emergence of infauna (Riedel et al., 2008a), unusual interactions including predation (Riedel et al. 2008b; Haselmair et al. 2010), altered locomotion and activity patterns (Pretterebner et al., 2012), and a clear sequence of mortalities (Riedel et al., 2012). For an overview of these responses see Riedel et al. (this issue) and a sample 4-day film at http://phaidra.univie.ac.at/o:87923.

The longer term implications are less well known. The collapse of benthic communities and recurring disturbances - hypoxia/anoxia, marine snow events, fisheries damage - raise fundamental issues of ecosystem stability and resilience. One approach to addressing these issues is to examine post-disturbance events and successions. Two basic recolonisation strategies have been described: motile species immigrating into denuded areas (smaller scale damage) or larval settlement by pelagic recruits (Pearson and Rosenberg, 1978; Whitlatch et al., 1998; Norkko et al., 2010). The reestablishment of community structure on northern Adriatic soft bottoms requires biogenic structures (bivalve and gastropod shells, sea urchin tests) on which larvae can settle. Sedimentation, however, can cover such structures and hamper new epigrowth (Zuschin and Stachowitsch, 2009). Compared to mortality events, recovery is a much longer term process. For example, in a Swedish fjord it took about $3 \mathrm{yr}$ after anoxia for the top sediment to recover to a state suitable for macrofauna recolonisation (Rosenberg, 1971). Recovery of benthic communities after experimental trawling in Scotland took more than 18 months (Tuck et al., 1998). Intertidal communities from muddy sand habitats also showed very slow biological and physical recovery rates (Dernie et al., 2003). In the northern Adriatic, Stachowitsch and Fuchs (1995) were unable to detect full recovery after an oxygen depletion event even after more than ten years, whereby recolonisation was repeatedly interrupted by commercial fishing damage
(Kollmann and Stachowitsch, 2001). Elsewhere in the northern Adriatic, Rapido trawling significantly changed community structure and mean abundance of common taxa (Pranovi et al., 2000), and beam trawling is also known to alter the physical characteristics of the sea floor (Kaiser and Spencer, 1996). Such bottom sampling equipment can, in turn, increase oxygen consumption and nutrient concentrations and promote phytoplankton primary production, which changes overall community structures over the long term (Riemann and Hoffmann, 1991; Jennings and Kaiser, 1998).

When long-lived, sessile suspension feeders are reduced by disturbances, benthic communities often experience a shift to mobile detritus feeders; their activities can hinder recovery (Dayton et al., 1995). Such altered communities are often dominated by juvenile stages, mobile species and rapid colonisers (Pearson and Rosenberg, 1978). In the northern Adriatic Sea, for example, hermit crab numbers increased over a $5 \mathrm{yr}$ period after anoxia, but the proportion of the keystone organisms such as brittle stars, sponges and ascidians remained low (Kollmann and Stachowitsch, 2001). Such long-term recovery processes make benthic communities the "memory" of disturbances (Stachowitsch, 1992).

The present work assesses both the immediate, short-term scavenging processes and the longer term recovery processes after artificially induced anoxia in the northern Adriatic Sea. Based on the rapid attraction of scavengers to baited traps as well as the rapid removal of discards and moribund benthos in the beam-trawl fishery for flatfish in the North Sea (Groenewold and Fonds, 2000), coupled with the high density of potential predators and scavengers in the Adriatic, we hypothesize that attracted scavengers quickly remove the damaged benthos. Although we expect full recovery (establishment of multi-species clumps) to be a longer term process, we also hypothesize that, based on the small scale of our experiments, recovery will be initiated relatively rapidly (i.e. weeks to months). We tested our hypotheses in two plots after experimentally induced anoxia using a time-lapse camera followed by longer term photographic series.

\section{Material and methods}

The activities of seven scavengers were examined. These encompass all the species that entered the experimental quadrats after the induced anoxia. The fact that six of the seven species were present in both experiments indicates that we have encompassed the typical set of organisms that potentially removes dead and moribund benthos in the study area. These scavengers included two invertebrates and four vertebrates: the muricid gastropod Hexaplex trunculus (Linnaeus, 1758), the hermit crab Paguristes eremita (Linnaeus, 1767), and four fish species: the demersal goby Gobius niger (Linnaeus, 1758) and comber Serranus hepatus (Linnaeus, 1758) as well as the benthopelagic bream Diplodus vulgaris 

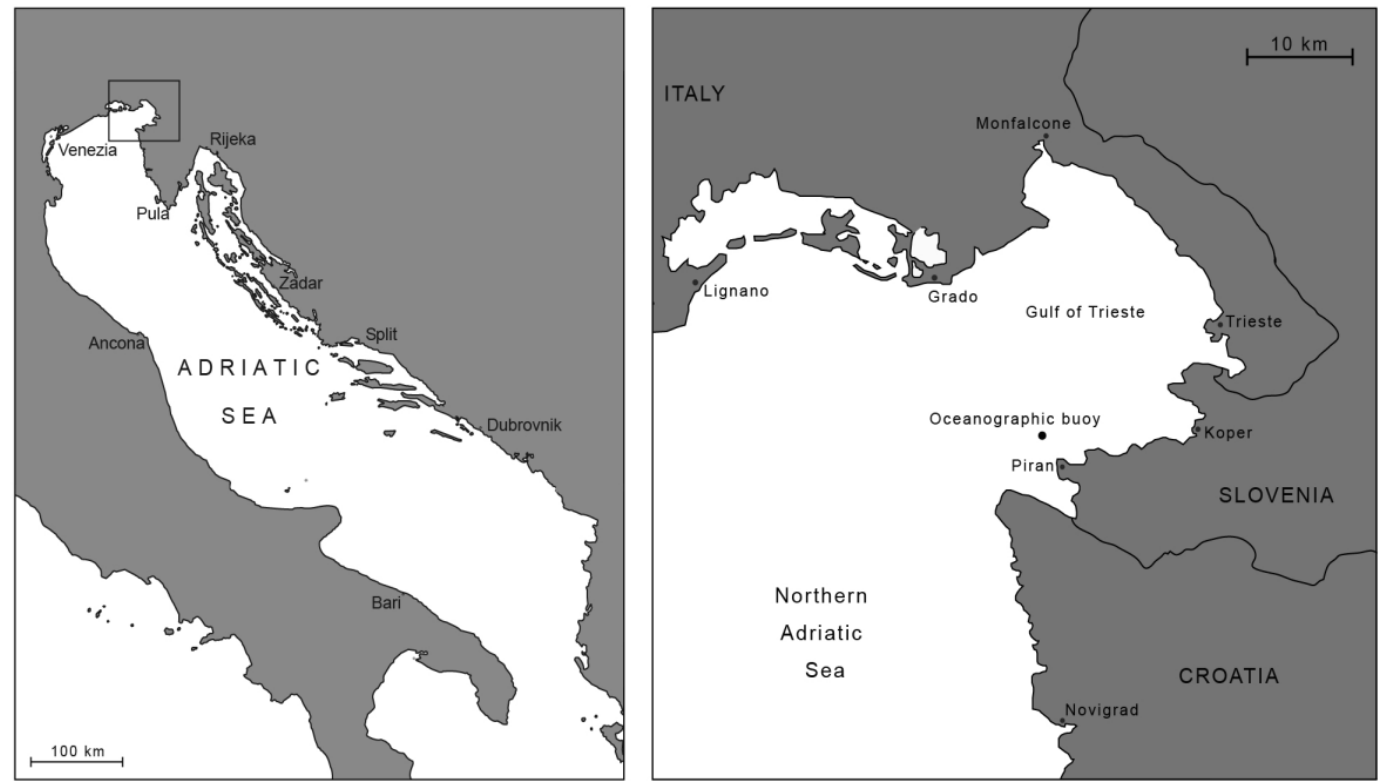

Fig. 1. Study site; the northern Adriatic Sea (left), oceanographic buoy off Piran in the Gulf of Trieste (right).

(Geoffroy Saint-Hilaire, 1817) and pandora Pagellus erythrinus (Linnaeus, 1758).

\subsection{Study site}

The study site is located in the Gulf of Trieste, northern Adriatic Sea $\left(45^{\circ} 32^{\prime} 55.68^{\prime \prime} \mathrm{N}, 13^{\circ} 33^{\prime} 1.89^{\prime \prime}\right.$ E) off Piran, Slovenia (Fig. 1). It is about $2 \mathrm{~km}$ offshore at a depth of $24 \mathrm{~m}$, near the oceanographic buoy of the Marine Biology Station in Piran. This position was chosen to minimise disturbance and damage by commercial fisheries. No evidence of trawling was found at the experimental site (fishing boats maintain a safety distance from the buoy, no anchoring by pleasure boats or sport fishers is permitted within $50 \mathrm{~m}$ ). The soft bottom is dominated by the ORM community described above. Directly under the buoy there is an accumulation of mussels that have fallen from the anchoring chains. This is associated with a higher density of gastropods, but our experimental plots were outside this immediate zone.

\subsection{Experimental set-up}

Two different benthic chamber configurations were used. The "closed configuration" creates anoxia by sealing a $50 \mathrm{~cm} \times 50 \mathrm{~cm} \times 50 \mathrm{~cm}$ volume off from the surrounding water with Plexiglass ${ }^{\circledR}$ walls. The "open configuration", in which the Plexiglass ${ }^{\circledR}$ chamber is replaced by an open frame of the same size, is designed to observe behaviour under normoxic/post-anoxic conditions. A lid on top of the chamber/frame holds a digital time-lapse camera (Canon EOS 30D) with a zoom lens (Canon EFS 10-22 mm), two battery packs (9Ah Panasonic, Werner light power, Unterwassertech- nik, Germany) and two flashes ("midi analog" series 11897; Subtronic, Germany). The battery packs, combined with a specially designed electronic control circuit, enable the equipment to be operated for about $72 \mathrm{~h}$. Finally, a datalogger (PA3000UD, Unisense, Denmark) and a sensor array for measuring oxygen, temperature and hydrogen sulfide are also located on the lid (for a detailed description see Stachowitsch et al., 2007). Images were produced at $3 \mathrm{~min}$ intervals, sensor data logged every minute.

This configuration was the largest chamber (and instrument lid) size that could be handled by divers at $24 \mathrm{~m}$ depth and is among the largest benthic chambers deployed on a sublittoral soft bottom. A greater volume was also hindered by the generally poor visibility in this area and corresponding short camera distance from the sediment. The chamber/frame was large enough to enclose bioherms and the surrounding sediment, and such larger chambers are also preferable in benthic oxygen uptake experiments over smaller chambers (and extrapolations therefrom) (Glud and Blackburn, 2002).

The present two experiments involved the following deployment protocol. The underwater device was initially positioned in its closed configuration over a representative multispecies clump (with both sponges and ascidians). After max. $72 \mathrm{~h}$, and creation of anoxia (visible in time-lapse films by mortality of the macrobenthos and blackened sediment confirmed to be associated with anoxia by sensor data in a series of earlier experiments using this benthic chamber), the lid was lifted and brought to the surface to exchange the battery packs and download the images (the chamber remained sealed with a cover). Immediately thereafter (overall surface procedure $<1 \mathrm{~h}$ ), the lid was again transported to the deployment site and the chamber replaced by the open frame, 
marking the beginning of the post-anoxia recovery experiment. Post-mortality scavenging was documented for about 3 days. Combined, the two deployments yielded a dense data set comprising $139 \mathrm{~h}$ of autonomous time-lapse recordings with a total of 2814 post-disturbance images.

\subsection{Short-term scavenging}

Two experiments were performed. In the first, postdisturbance images (open configuration) were taken from 15 August 2009 (10:35 a.m. LT) to 18 August 2009 (10:05 a.m.) ("August" experiment). The second experiment extended from 14 September 2009 (03:25 p.m.) to 17 September 2009 (10:49 a.m.) ("September" experiment). The August experiment yielded a total of 1430 images, the September experiment 1384 images. This corresponds to a documentation time of 71.5 and $67.5 \mathrm{~h}$, respectively. The images were also processed into time-lapse movies using the Adobe Premiere 6.5 program (August recovery time-lapse film available at http://phaidra.univie.ac.at/o:262380). The fishes were analysed image by image: the data are summarised in $6 \mathrm{~h}$ steps. Because of the relatively slow movements of the hermit crabs and gastropods and the more gradual changes in their numbers, only every tenth image was evaluated for these groups. For every analysed image, the number of individuals of each scavenger species were recorded. The different multi-species clump substrates (sponges, ascidians, sediment) that the hermit crabs and gastropods were on were recorded. Normally, these two taxa are found only on the sediment surface. We therefore equate the dead or moribund organisms they chose with their preferred prey items. The time and sequence of arrival/departure and the maximum number of individuals were recorded. The hour-values in the Results refer to the times after removal of the benthic chamber (and not to the time after anoxia was generated inside the chamber). Day/night activity (based on sunrise and sunset, www.sun.exnatura.org) of hermit crabs and gastropods was analysed.

Individual specimens of the same species could not always be differentiated throughout a deployment because coloration and sizes were typically very similar and the perspectives often changed considerably. Accordingly, we use "observations" and "number of observed specimens" to refer to the number of fish, gastropod and hermit crab "individuals", i.e. representatives of the species visible over the respective time period. Thus, a total of 12 gobies visible in $6 \mathrm{~h}$, for example, could in theory represent between 1 and 12 separate individuals. In these territorial fish, however, we expect the actual number of specimens to be at the lower end of the range. Equally, many crab and gastropod individuals remained in the plots for long periods. While the number of "observed specimens" clearly overestimates the actual number of different individuals present, it does reflect the overall scavenging influence exerted by the respective species during that time.

\subsection{Longer term recovery}

These experiments were conducted on the same two $0.25 \mathrm{~m}^{2}$ plots used for the time-lapse camera study. The predisturbance surface area occupied by living sponges and ascidians, as well as by other hard structures and lebensspuren, was calculated using CorelDraw9 and Excel 2010 based on the photos taken from the closed configuration. The corresponding surface areas were then measured again days to years after anoxia. The area occupied by recolonizers was calculated as a measure of recovery. Each plot was subdivided into four quadrants and an image taken of each quadrant with a hand-held camera (i.e. four macro-photos per plot per sampling date). The images of the August plot were taken on 18 (day 1 of long-term experiment), 22, 24 and $25 \mathrm{Au}-$ gust 2009, those of the September plot on 19 (day 1 of longterm experiment), 20, 23, and 30 September 2009. Both plots were also photographed twice in each following year, namely, on 7 and 17 August 2010, and 6 and 7 August 2011. The objects were classified into four categories: (1) sessile fauna (living/dead) and anemones, (2) shells (bivalves and gastropods), (3) small pieces of shells and areas covered with many shell fragments ("coquina") and (4) lebensspuren from vagile fauna and endofauna burrow openings (data not presented).

To better compare the two experiments, the times when the images were taken were categorised (e.g. 7-13 days is termed " 10 days" in the following text). The data in the two sets of photographs taken in short succession at $1 \mathrm{yr}$ and $2 \mathrm{yr}$ at each plot are averaged, and referred to as " $1 \mathrm{yr}$ " and " $2 \mathrm{yr}$ ", respectively, unless stated otherwise.

Time series analyses and cross correlations were calculated to define the residence time of gastropods and hermit crabs in the plots. Graphs of time series analysis can be found in Blasnig (2012). For statistical analyses the program Past was used (Hammer et al. 2001).

\section{Results}

\subsection{Short-term scavenging after anoxia}

Moribund and dead sponges and ascidians attracted fishes, hermit crabs and gastropods in a rapid and distinct sequence. Numerous fishes arrived in the first hours. They were followed by hermit crabs (Paguristes eremita), which showed a rapid initial increase in the number of individuals. Finally, the gastropods (Hexaplex trunculus) appeared (Fig. 2), with a slow increase of individuals.

\subsection{The fishes}

In the August 2009 experiment ( $71.5 \mathrm{~h})$, we observed three different species, Diplodus vulgaris, Serranus hepatus and Gobius niger, and additionally in the September 2009 experiment $(67.5 \mathrm{~h})$ we observed Pagellus erythrinus. In both 


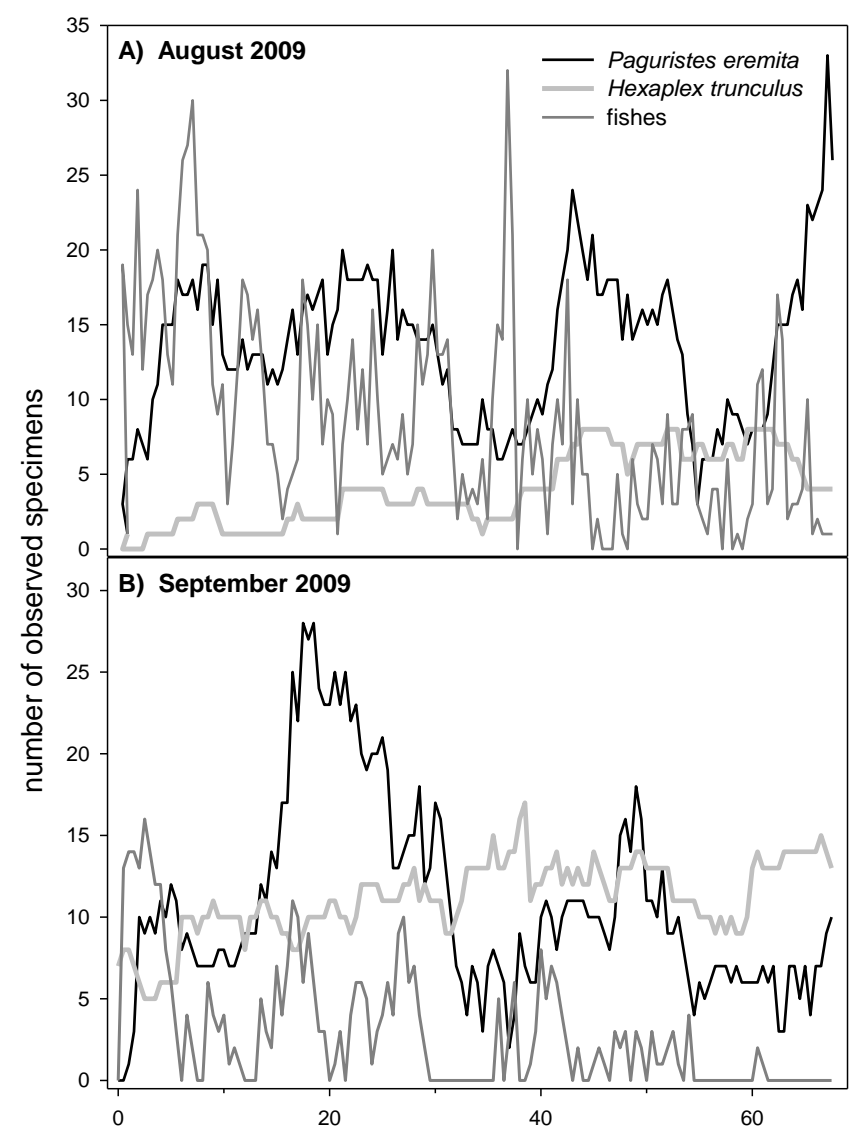

Fig. 2. (A) Arrival and presence of fishes, hermit crabs and gastropods after anoxia at the August 2009 plot and (B) September 2009 plot.

experiments, the maximum number of observations per species occurred in the first $6 \mathrm{~h}$. G. niger was most abundant and showed a slowly decreasing trend, while the other species decreased rapidly to very low numbers. A maximum of three species were visible at the same time in a single image.

In the first $6 \mathrm{~h}$ of the August experiment, all three species were present: G. niger with $83, D$. vulgaris 35 and $S$. hepatus 26 observations. The two latter species then decreased to very low numbers or zero in the successive $6 \mathrm{~h}$ periods. G. niger also decreased with time, but never fell below 22 observations per $6 \mathrm{~h}$ (i.e. total number visible over this time period, not necessarily different individuals, see Material and Methods).

In the September experiment, all four species were initially present and showed the highest abundance in the first 6h time step: G. niger peaked with 80,D. vulgaris 18 and $S$. hepatus 13 observations. The number of observations decreased markedly by the end of the experiment.

\subsection{The first $12 \mathrm{~h}$ : hermit crabs and gastropods}

The first $12 \mathrm{~h}$ were evaluated separately to better determine the order in which the species and individuals arrived. In August, the first three Paguristes eremita were observed after 30 min and the number rapidly increased up to 19 individuals after $9 \mathrm{~h}$. After $3 \mathrm{~h}$ the first Hexaplex trunculus arrived and the number slowly increased to three individuals after $8 \mathrm{~h}$ (Fig. 2a). In September, the first $P$. eremita appeared after $1 \mathrm{~h}$, and numbers then increased up to 12 individuals after $6 \mathrm{~h}$, before decreasing again to nine. Seven $H$. trunculus individuals survived the anoxia (Fig. 2b) and were present and visible from the start. After $30 \mathrm{~min}$ the first new gastropod entered the frame. Two hours later, three individuals again left the area (5 present), but thereafter the number increased steadily (max. 17).

\subsection{Day/night activity}

In both experiments the number of Paguristes eremita varied considerably over time. The values decreased in all three nights examined and increased conspicuously during daylight hours (Fig. 3). During the "day" the number of observed specimens in August increased to 24 ( $45.5 \mathrm{~h}$ after closed chamber removal) and 33 (after $71 \mathrm{~h}$ ), while at night, values fell to six and to three (after 38 and $58 \mathrm{~h}$, respectively). In September, the number peaked during daylight at $28(17.5 \mathrm{~h}$ after closed chamber removal) and dropped to only two (after $37 \mathrm{~h}$ ) and three observations (after $62.5 \mathrm{~h}$ ). The time series analysis for $P$. eremita showed highly significant peaks at $21.2 \mathrm{~h}$ (August), 28.4 and $54 \mathrm{~h}$ (September), a significant peak at $12.4 \mathrm{~h}$ (August), and distinct but not significant peaks at 15.5 and $57.2 \mathrm{~h}$ (August) and at $10.8 \mathrm{~h}$ (September) (Chisquared test, data not shown). These peaks demonstrate a semidiurnal and diurnal periodicity.

Hexaplex trunculus showed a relatively slow but constant increase, levelling off somewhat over the last day. The peak number was eight observations at three periods between 46.5 and $65.5 \mathrm{~h}$ in August, and 17 observations after $38.5 \mathrm{~h}$ in September. At the end of both experiments, 4 (August: $71.5 \mathrm{~h}$ ) and 13 (September: $67.5 \mathrm{~h}$ ) H. trunculus were still present in the plots. The time series analysis showed highly significant peaks (data not shown) at 18.5 and $38.1 \mathrm{~h}$ (August) as well as 13.5, 27.0 and $60.0 \mathrm{~h}$ (September). Visible but not significant peaks are present at 8.2, 9.7 and $11.2 \mathrm{~h}$ (August) as well as at $18 \mathrm{~h}$ (September). These peaks point to a periodicity of nine and $12 \mathrm{~h}$ as well as multiples thereof.

The fishes show highly significant (data not shown) peaks at $9.9 \mathrm{~h}$ (August) as well as 12.3 and $21.6 \mathrm{~h}$ (September) and visible but not significant peaks at $30.1 \mathrm{~h}$ (August) 6.4 and $7.8 \mathrm{~h}$ (September)(Fig. 2). This points to a semidiurnal and a roughly diurnal periodicity. 


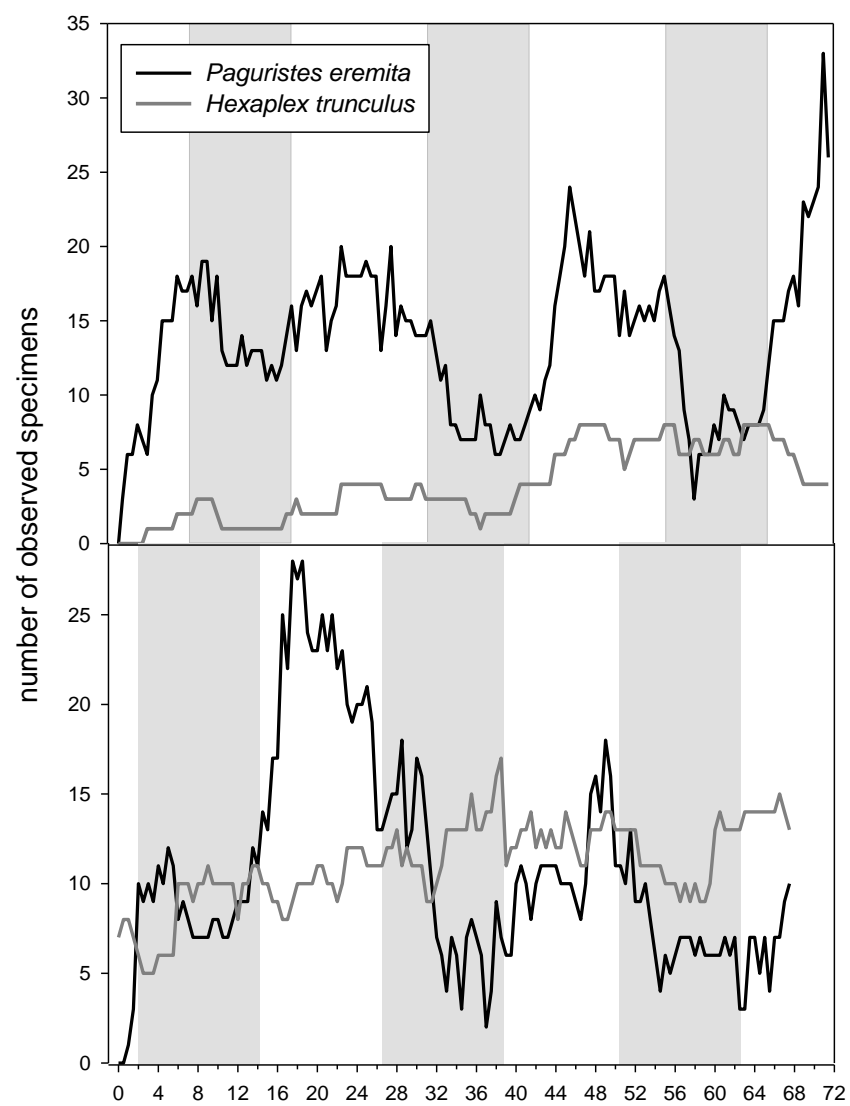

Fig. 3. Day/night activity of Paguristes eremita and Hexaplex trunculus after anoxia. White bars mark daylight hours, grey bars night hours. Above: August 2009 plot, below: September 2009 plot. Night is about $1 \mathrm{~h} 30 \mathrm{~min}$ longer in September.

\subsection{Preferred substrates/prey items}

The substrates that Paguristes eremita and Hexaplex trunculus chose were different and consistent in both experiments. Hermit crabs were observed on the sediment, on sponges and on ascidians, whereas $H$. trunculus occurred mainly on ascidians and to a lesser extent on the sediment (Fig. 4). All categories (i.e. compared species-experimental month pairs) are significantly different from each other. Importantly, there are bigger interspecific than intraspecific differences: the differences between the species ( $P$. eremita in August and September versus $H$. trunculus in August and September) are bigger than between the months $(P$. eremita in August versus September and $H$. trunculus in August versus September) (Chi Square test, data not shown).

The duration of the stay of nine Paguristes eremita and nine Hexaplex trunculus was calculated. The individuals were chosen based on their recognizability (e.g. shell epigrowth). This duration averaged $5 \mathrm{~h}$ and $19 \mathrm{~min}$ for $P$. eremita and $12 \mathrm{~h}$ and $9 \mathrm{~min}$ for $H$. trunculus. Thus, on average, the gastropods stayed more than twice as long as the crabs. In the August experiment, several $P$. eremita dragged

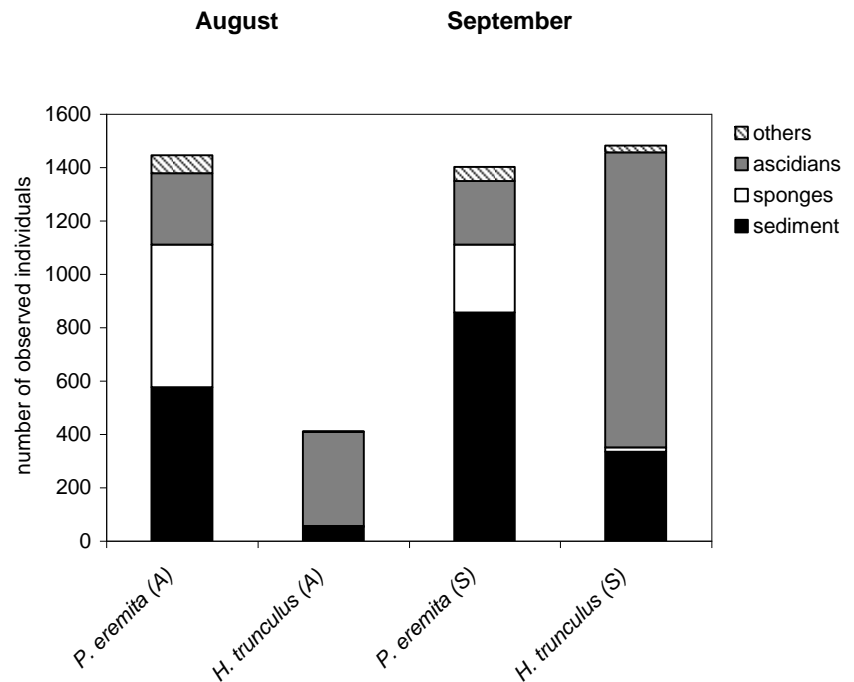

Fig. 4. Substrates/prey chosen after anoxia by Paguristes eremita and Hexaplex trunculus in the August 2009 (A) and September 2009 (S) experiments ("others": frame or substrate other than sponges, ascidians or sediment).

off the ascidian Phallusia mammillata. Within $53 \mathrm{~h}$, they dragged it (along with an attached anemone Cereus pedunculatus and the ascidian Microcosmus sp.) $8 \mathrm{~cm}$ in one direction, then $21 \mathrm{~cm}$ in the opposite direction, just outside the frame. The ascidian, which had become discoloured, was then partially consumed by the end of the film, with pieces being visibly removed.

\subsection{Sea anemones}

The August experiment contained three Cereus pedunculatus: two attached to ascidians (Microcosmus sp. and P. mammillata), one next to a large sponge. All three survived the anoxia but showed extreme elongation and rotations. One was carried outside the frame by hermit crabs (attached to P. mammillata, see above), the second was also flipped out of the frame (attached to Microcosmus), probably by hermit crabs.

The third individual, immediately adjacent to the sponge, fully emerged from the substrate and began to crawl away after $66 \mathrm{~h}$ and $15 \mathrm{~min}$ of re-oxygenation. At the end of the short-term post-disturbance evaluation ( $71.5 \mathrm{~h}, 18$ August) the specimen was still inside the frame. During the subsequent longer term evaluation this anemone was still alive and visible at that position on the image of 22 August. Two days later, it disappeared from the images.

\subsection{Longer term recovery}

At the start of the August experiment, $1939 \mathrm{~cm}^{2}(77.5 \%)$ were covered by sessile organisms and $540 \mathrm{~cm}^{2}(21.5 \%)$ by vagile fauna (mostly hermit crabs and gastropods; 

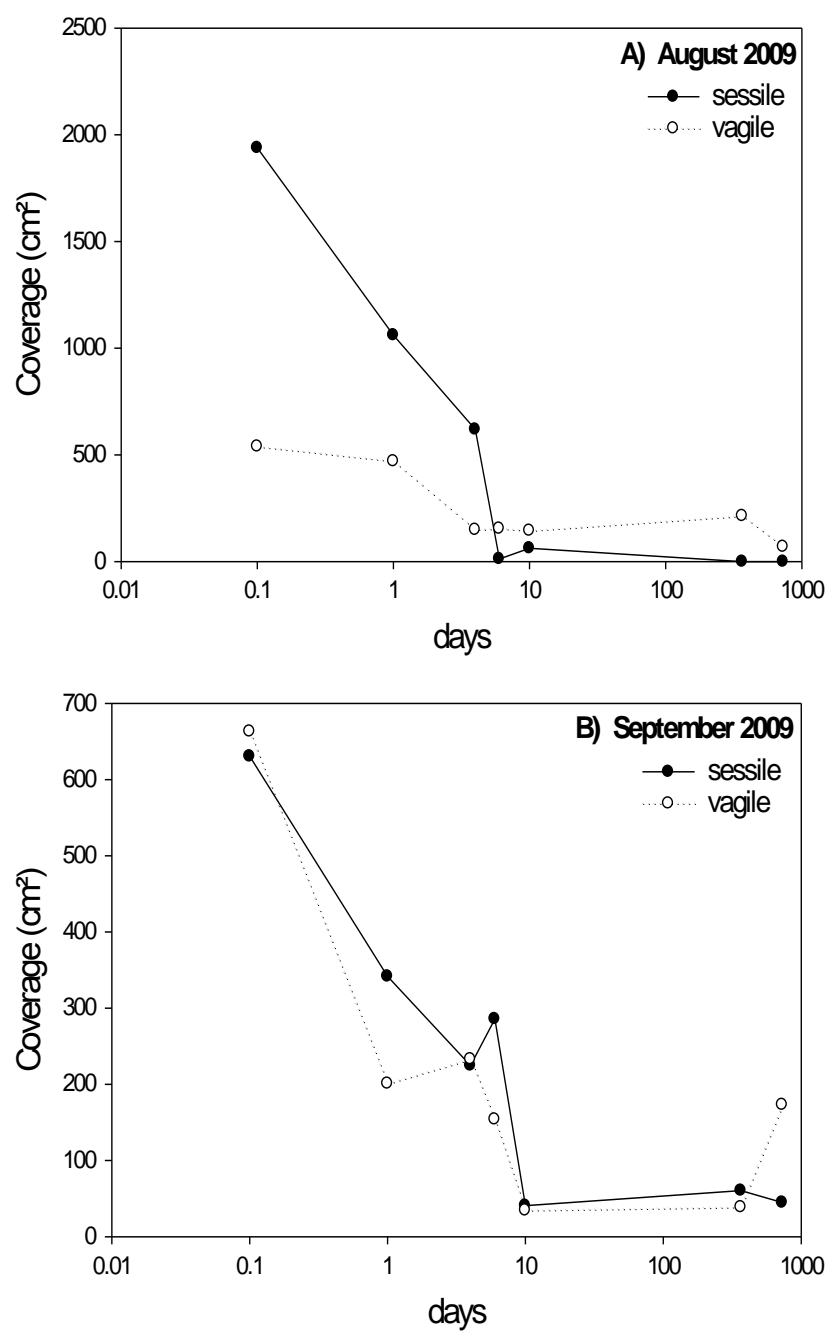

Fig. 5. Coverage of sessile (dead and living) and vagile fauna after anoxia in the August 2009 (above) and September 2009 (below) plot. Note different scales on $y$ axis. Start of experiment defined as 0.1 ; values measured inside closed chamber (original coverage).

total values can approach or exceed $100 \%$ because animals on living substrates were counted separately). After the initial increase in scavengers (see above), the vagile fauna decreased markedly to $155 \mathrm{~cm}^{2}$ coverage $(6 \%)$ by day six of the long-term experiment (Fig. 5a). The sessile fauna dropped to $12 \mathrm{~cm}^{2}(0.5 \%)$. In September, the sessile fauna initially covered $631 \mathrm{~cm}^{2}(25 \%)$, the vagile fauna $663 \mathrm{~cm}^{2}(26.5 \%)$. As in August, both groups decreased drastically, with closely parallel trends (Fig. 5b). After six days, the sessile fauna fell to $286 \mathrm{~cm}^{2}(11.5 \%)$, the vagile fauna to $154 \mathrm{~cm}^{2}(6 \%)$. In the " 10 day" category (see Material and Methods), nearly the whole fauna was consumed (sessile) or had moved away (vagile). Both 1 and $2 \mathrm{yr}$ after the start of the experiment, no macroscopic sessile epifauna was observed on either plot. The exception was one sea anemone, Cereus pedunculatus,
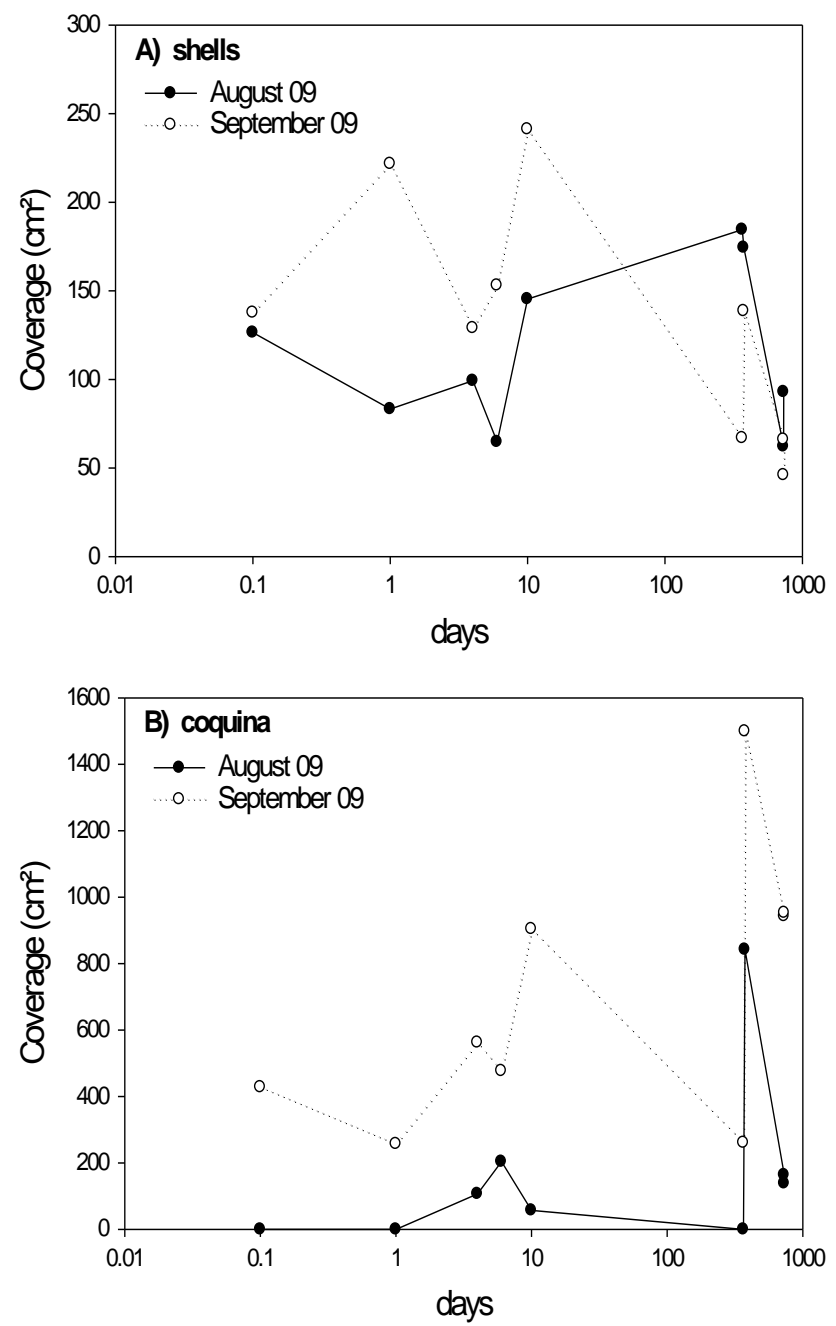

Fig. 6. Coverage of shells after anoxia of the August and September 2009 plot (above) and of coquina (below). Note different scales on $y$ axis. Start of experiment defined as 0.1 and initial values measured inside closed chamber (original coverage).

in the September experiment; it survived anoxia and was still present in both following years.

Shells $(>1 \mathrm{~cm})$ and smaller shelly material ("coquina": smaller shells and shell fragments forming loose aggregations on top of the sediment) were visible in both plots (Fig. 6a, b). Overall, in both experiments shell coverage (Fig. 6a) fluctuated but showed similar values at the beginning and end ( $2 \mathrm{yr})$. In August, cover increased from an initial $126 \mathrm{~cm}^{2}$ to $185 \mathrm{~cm}^{2}$ after $1 \mathrm{yr}$, with a drop after $2 \mathrm{yr}$ to $62 \mathrm{~cm}^{2}$. In September, coverage decreased 1 and $2 \mathrm{yr}$ postanoxia, with a minimum of $46 \mathrm{~cm}^{2}$ after " $2 \mathrm{yr}$ ". Interestingly, short-term fluctuations occurred, for example between the $1 \mathrm{yr}$ and the $1 \mathrm{yr}+10$-day sampling $\left(67\right.$ versus $\left.139 \mathrm{~cm}^{2}\right)$.

Coquina coverage (Fig. 6b) fluctuated more widely and clearly increased over time. The trend in the two experiments 
was less similar, with values in the September experiment always exceeding those of August.

In August, no coquina was initially observed, but after 34 days the coverage increased to $204 \mathrm{~cm}^{2}$. After " 10 days" it fell again to $57 \mathrm{~cm}^{2}$, followed by a peak of $842 \mathrm{~cm}^{2}$ after $1 \mathrm{yr}+10$-days. Note, however, that 10 days earlier, the value was zero, showing the potential for major fluctuations even over short time periods. In September, values initially decreased from $428 \mathrm{~cm}^{2}$ to $257 \mathrm{~cm}^{2}$, but then steadily increased to $904 \mathrm{~cm}^{2}$, dropping after 1 year to $261 \mathrm{~cm}^{2}$ but peaking again at $1499 \mathrm{~cm}^{2}$ after an additional 10 days (i.e. $1 \mathrm{yr}+10$-day sampling). Thus, values changed considerably within even a 10 day period. With few exceptions (early August), coquina always covered more surface than shells.

\section{Discussion}

In the northern Adriatic, hypoxia/anoxia cause rapid mortalities of macroepibenthic communities (Stachowitsch, 1984; Kollmann and Stachowitsch, 2001), but little is known about post-anoxia processes other than that recolonisation is apparently slow and additionally hampered by bottom trawling (Stachowitsch, 1991). The present study extends prior investigations on the behavioural responses and mortality sequences (Riedel et al., this issue, and references therein) using a specially designed underwater chamber and time-lapse system. It helps fill in the gap between community collapse and recolonisation by examining short-term scavenging and longer term recovery processes.

\subsection{Short-term post-anoxia scavenging}

After anoxia, the moribund and dead organisms quickly attracted scavengers. This confirms our first hypothesis that the attracted scavengers quickly remove the damaged benthos. The process resembles that described after simulated benthic fisheries damage to scallops in the north Irish Sea (Jenkins et al., 2004): while baited, heavily damaged scallops were eaten within $24 \mathrm{~h}$, lightly damaged individuals were inaccessible until large crustaceans (Cancer pagurus) made the body tissue available, causing protracted aggregation and feeding for up to $96 \mathrm{~h}$. Our dead organisms were shell-less, but the tunics of ascidians, for example, probably also delayed access by less powerful hermit crabs or small gobiids, explaining the presence of scavengers at the end of the experiments (67.5 and $71.5 \mathrm{~h})$.

The images revealed a clear sequence of scavengers. We attribute the quick arrival of fishes mainly to their swimming speed (e.g. Diplodus vulgaris: $12.3 \mathrm{~cm} \mathrm{~s}^{-1}$; Planes et al., 1997), which is orders of magnitude faster than the next arrival, Paguristes eremita $\left(21.6 \mathrm{~m} \mathrm{~d}^{-1}\right.$, average speed $2.1 \mathrm{~m} \mathrm{~h}^{-1}=3.5 \mathrm{~cm} \mathrm{~min}^{-1}$; Stachowitsch, 1979). Other factors include distance from the disturbance and the size of the disturbed area. Gobius niger has an estimated density of about 1 individual $10 \mathrm{~m}^{-2}$, Serranus hepatus 1 individual $22 \mathrm{~m}^{-2}$ (Wurzian, 1982), so that we expected individuals to be close by. These densities would also help explain the relative proportions we recorded of these two species: Gobius is more abundant and its numbers in the images were more than twice as high as those of Serranus. Based on the speeds of other, smaller gastropods (e.g. Littorina littorea, $2.88-4.47 \mathrm{~cm} \mathrm{~min}^{-1}$; Erlandsson and Kostylev, 1995) and on the similar size of large P. eremita and adult $H$. trunculus, we believe the speeds of the hermit crab and gastropod are similar. In such cases, arrival times would depend on density, with more abundant species having a greater probability of having individuals close by. In this benthic community, $P$. eremita has a density between 1.9 individuals $\mathrm{m}^{-2}$ (quadrat sampling; Stachowitsch, 1977) and 2.4 individuals $\mathrm{m}^{-2}$ (transect method: Pretterebner et al., 2012). H. trunculus, in turn, has a density of 0.2 individuals $\mathrm{m}^{-2}$ in the ORM community (Wurzian, 1982), although the value may be slightly higher here due to the proximity of the oceanographic buoy (see Material and Methods, "study site"). This explains why the gastropods arrived last.

Fishes were conspicuously abundant in the first six hours after switching to the open frame. This is the time when the most food items were available, including smaller softbodied infaunal organisms freshly emerged from the sediment and cryptic fauna from multi-species clumps. The fishes were dominated by Gobius niger, which feeds on polychaetes, amphipods, mysids and decapods (Richards and Lindeman, 1987). Pagellus erythrinus mainly preys on benthic organisms such as polychaetes, brachyuran crabs and benthic crustaceans (Fanelli et al., 2011), Serranus hepatus on invertebrates, mainly decapods (Labropoulou and Eleftheriou, 1997), and Diplodus vulgaris on benthic echinoids such as Echinocyamus pusillus and Psammechinus microtuberculatus, but also on decapods and bivalves (Pallaoro et al., 2006). In the present study, $P$. eremita and $H$. trunculus mainly fed on material that remained after the fishes had already been present for several hours: based on their positions, mostly ascidians (Phallusia mammilata, Microcosmus spp.) and sponges. The time-lapse camera approach was unable to provide direct evidence that the fishes also fed on sponges or ascidians, although the fish were often positioned in an oblique angle with the mouth facing down. Many ascidians and sponges rely on chemical antipredator defences (e.g. Pawlik, 1993). Ascidians also exhibit physical defences (e.g. tunic toughness: Koplovitz and McClintock, 2011). The latter mechanism may still be effective in freshly dead individuals, making them unattractive for small fishes as the quickest arrivals. Young (1989), for example, observed ascidians being eaten by gastropods, which insert their proboscis into their siphon. Our evaluation showed some $H$. trunculus on the siphon of Microcosmus spp., but other individuals were positioned on other parts of the ascidians.

To better determine food preferences, we evaluated the substrates on which the scavengers positioned themselves, 
equating the chosen dead or moribund species with the preferred prey. In some cases, these substrates were clearly eaten and reduced in size. While both species fed on sponges and ascidians, $H$. trunculus was much more frequently positioned on Microcosmus. The August images also showed $P$. eremita dragging off and consuming an ascidian (Phallusia mammillata). $H$. trunculus, in contrast, crawled up the ascidians and typically remained there for several hours: on average, the gastropods stayed within the frame about $7 \mathrm{~h}$ longer than the crabs. This agrees with Sawyer et al. (2009), who documented 10.5, 5.2 and $2.9 \mathrm{~h}$ for feeding and manipulating the mussel prey in three selected $H$. trunculus individuals in this community. Under normoxic/undisturbed conditions, hermit crabs and gastropods are found almost exclusively on the sediment, not on bioherms, so that we have never observed this type or this level of scavenging before.

The semi-diurnal and diurnal rhythm of $P$. eremita adds a new facet to the hermit crab's activity behaviour. Stachowitsch (1979) recognised two types of movement interruptions based on time-lapse films: short stops related to feeding and investigating structures on the sediment and longer pauses during the night hours reflecting a resting period, i.e. fewer individuals therefore moving on or across the quadrats at night. Our explanation for why fewer individuals remained in the plot near their prey items at night in the present experiments is that, in their dormant night phase, crabs might move away from larger prey because staying would increase the risk that they themselves would be consumed, along with the prey, by other, larger (fish) predators/scavengers. The same may hold true for $H$. trunculus based on the 9 and $12 \mathrm{~h}$ periodicity indicated by the time series analysis (Blasnig, 2012).

As a scavenger, the gastropod $H$. trunculus has one advantage over the hermit crab $P$. eremita: it is among the most anoxia-tolerant species in this soft-bottom community (Riedel et al., 2012). All individuals survived anoxia in our September experiment and were therefore immediately present upon re-oxygenation. Molluscs, for example, are generally considered to be more tolerant to hypoxia than many other invertebrate groups (Vaquer-Sunyer and Duarte, 2008). Such tolerance not only improves survival but may also enable more successful predation during and after hypoxia events (Pihl et al., 1992). Although no P. eremita survived anoxia in this study, this species is among the most tolerant crustaceans in this community (Riedel et al., 2012), making them potential predators and scavengers during and after shorter mild to moderate hypoxia. In our experiments, the abundant presence of both species in the same plots, and their preference for different substrates/prey, suggest no mobile species interactions (i.e. no competitive interactions for food). Depending on the severity and duration of oxygen depletion, both species may be able to take advantage of more vulnerable prey. Such altered predator-prey relationships may affect community structure. Moreover, the size of the disturbed area is important: in larger areas in which gastropods have survived but hermit crabs did not, the gas- tropods would have a lengthy advantage before the crabs from outlying regions can repopulate the affected area. Our experimental set-up is unable to mimic that scenario, which could only be tested in future natural collapses. Scaling up presents numerous practical problems (Zajac et al. 1998): simply capturing the short post-anoxia scavenging phase is a challenge in itself, probably explaining the lack of information on such scavenging elsewhere.

The sea anemone Cereus pedunculatus - as the only surviving macrofaunal organism beyond $H$. trunculus - showed an unexpected post-anoxia behaviour. It crept away from its original position $66 \mathrm{~h}$ and $15 \mathrm{~min}$ after the chamber was opened. Anemones, although normally firmly attached, can move, and some hermit crabs for example can detach and reattach symbiotic anemones to their shells. The movement of C. pedunculatus in our experiment is intriguing because it occurred after re-oxygenation rather than during anoxia. One explanation is that the high density of post-anoxia feeding hermit crabs and gastropods disturbed the anemone. Alternatively, the adjoining dead sponge in that plot may have caused unfavourable conditions. Accordingly, the post-anoxia disturbance by aggregating scavengers was apparently more severe than the effect of anoxia itself: in none of the many other behavioural experiments we conducted did anemones ever move away during severe hypoxia or anoxia (with or without $\mathrm{H}_{2} \mathrm{~S}$ conditions), although they showed severe stress reactions (body contractions, rotation, extension; Riedel et al., this issue).

\subsection{Longer term recovery}

Even 2 yr after anoxia, no macroepibenthic recovery occurred in either of our plots. This contradicted our second hypothesis that recovery will be initiated rapidly at the relatively small scale of our experiments. Our conclusions are not a function of image resolution (macro-photos), and sample collection would not have yielded recruit epigrowth. Benthic recolonisation is, no doubt, scale dependent and can involve larval settlement (larger scale, longer term) and immigration by vagile organisms (smaller scale, shorter term) (Günther, 1992; Whitlatch et al., 1998). Past mortalities in the northern Adriatic Sea ranged from several $\mathrm{km}^{2}$ (Stachowitsch, 1992) to thousands of square kilometres (Stefanon and Boldrin, 1982). In our small-scale experiments, both recolonisation strategies are conceivable, but we would expect immigration to play the more immediate role. However, replacement of the sponges and ascidians that form the characteristic multispecies clumps may be more difficult than thought, despite adjoining bioherms (as larval producers) and vagile organisms (as immigrants).

Based on the abundant lebensspuren (data not shown), vagile species did criss-cross the denuded surface, but this does not lead to recolonisation with bioherms. Nonetheless, vagile fauna plays the key post-anoxia scavenging role. The rapid removal of moribund or dead sponges and ascidians 
within the first six days (August) and 13 days (September) after anoxia is attributed to the fauna that entered the experimental plots (or by the H. trunculus that survived inside the plots). The subsequent decline in food items was correlated with a corresponding drop in scavengers. The vagile fauna photographed in the plots after 1 and $2 \mathrm{yr}$ consisted mainly of $P$. eremita, $H$. trunculus, the sea urchin Psammechinus microtuberculatus and the brittle star Ophiothrix quinquemaculata. Kollmann and Stachowitsch (2001) consider lebensspuren to be helpful in quantifying community status and activity of mobile forms. The lebensspuren coverage in our plots (data not shown) points to abundant vagile fauna here. Such high densities, however, may also keep larval recruits low: grazing on and manipulation of the shells that the multi-species clumps initially require to grow on (Zuschin et al., 1999) could also help explain the lack of recovery. This could be interpreted as a disturbance agent although, as opposed to fishing gear, no physical damage occurs.

We explain the unexpected lack of longer term recolonisation with the fact that settlement and growth of sessile organisms depend on the presence of adequate substrates. In the northern Adriatic, these are typically empty gastropod and bivalve shells or echinoderm tests (Zuschin and Stachowitsch, 2009 and references herein). Although we recorded shells in our plots, they were apparently not large enough, sufficiently exposed, or available at larval settlement times. Thus, the percent coverage by shells fluctuated and ultimately declined after $2 \mathrm{yr}$. Small-scale factors that affect availability include manipulation by vagile species or removal (use as camouflage) by the sea urchins. One shortcut to the establishment of multi-species clumps in this community - the deposition of heavily encrusted gastropod shells by hermit crabs (Stachowitsch, 1980) - did not take place within our two plots in the two years examined.

Beyond biological factors, anthropogenic factors play a role which we could not mimic with our plots. Nonetheless, outside the protected zone around the oceanographic buoy, fishery gear such as dredges and bottom trawls leaves deep tracks, crushes multi-species clumps, shears off structures projecting from the bottom (e.g. pen shells), and overturns shells, impacting invertebrates growing on them (Stachowitsch and Fuchs, 1995). Fisheries and the passage of large ships also re-suspend enormous amounts of sediment, creating major turbidity and sedimentation events. Such anthropogenic resuspension is at work in our experimental site, where water currents can transport such suspended matter from afar. This sedimentation may also hinder larval-based recolonisation and epigrowth by covering available hard substrates. Such activities or events may help explain the considerable variation in the visible coverage by shells and the sudden changes in visible coquina within only a few days.

Anoxia-related disturbance and recovery in the northern Adriatic has been described as "rapid death - slow recovery" (Stachowitsch, 1991): most organisms die shortly after anoxia is attained, but recovery takes years. The ORM community showed little recovery 10 years after the collapse in 1983; although certain vagile fauna such as hermit crabs increased, larger multi-species clumps did not develop. This was attributed to repeated anoxia and fisheries damage (Stachowitsch and Fuchs, 1995; Kollmann and Stachowitsch, 2001). Recovery is therefore also determined by the frequency of disturbance. In wide areas of the Gulf of Trieste, northern Adriatic, oxygen depletion and the above combination of factors have altered the community structure observed by Fedra et al. (1976) in the early 1970s. This points to the difficulty in restoring community structure and function in the northern Adriatic. It also supports the notion that recovery from human disturbances takes longer than from natural disturbances and, in complex marine ecosystems with slow successions, recovery could take decades or longer (Jones and Schmitz, 2009; Lotze et al., 2011b). It is therefore not surprising that we failed to observe any recovery of sessile organisms during our experiments. Despite prior knowledge about lengthy recovery based on diver observations, random scuba-diver-taken samples and phototransect work (Kollmann and Stachowitsch, 2001), this study is the first to confirm the lack of recovery in specific quadrats with known pre-anoxia macroepifauna composition.

Using small-scale experiments to predict larger-scale recolonisation and succession is difficult because the combined factors controlling these processes at different spatial scales may differ fundamentally (Zajac et al. 1998). Despite our relatively small plot size and lack of replication, we nonetheless argue that our results are a step forward in distinguishing potential post-anoxia scenarios after differently sized collapses. Thus, the sequence of arrivals (fish, hermit crabs, gastropods) - related to their relative speeds and densities - and the roles the organisms played shed light on potential larger-scale phenomena. In extensive anoxic events, immediate immigration would be slower due to the greater distances involved, but the sequence of arrivals would presumably be the same. Surviving species (gastropods) would have a long-term scavenging advantage to the exclusion of more sensitive immigrants. Despite the inherent problems of scale, our results point to alarming long-term effects and call for intensive management measures to reduce further pollution and physical destruction of shallow-marine environments.

Acknowledgements. We would like to thank the director and staff of the Marine Biology Station in Piran for their support during this project. Alexandra Haselmair and Ivo Gallmetzer provided considerable support (diving and otherwise) during the fieldwork and took several sets of photographs for the longer term aspect. Philipp Steiner was a valuable participant in several field campaigns. Borut Mavric took one set of underwater photographs of the two plots in 2010. This study was financed by the Austrian Science Fund (FWF; project P21542 B17).

Edited by: J. Bernhard 


\section{References}

Blasnig, M: Short-term post-mortality predation and scavenging and longer-term recovery after anoxia in the Northern Adriatic Sea, Master's thesis, University of Vienna, Vienna, 2012.

Coll, M., Piroddi, C., Steenbeek, J., Kaschner, K., Ben Rais Lasram, F., Aguzzi, J., Ballesteros, E., Bianchi, C. N., Corbera, J., Dailianis, T., Danovaro, R., Estrada, M., Froglia, C., Galil, B. S., Gasol, J. M., Gertwagen, R., Gil, J., Guilhaumon, F., Kesner-Reyes, K., Kitsos, M.-S., Koukouras, A., Lampadariou, N., Laxamana, E., López-Fé de la Cuadra, C. M., Lotze, H. K., Martin, D., Mouillot, D., Oro, D., Raicevich, S., Rius-Barile, J., Saiz-Salinas, J. I., San Vicente, C., Somot, S., Templado, J., Turon, X., Vafidis, D., Villanueva, R., and Voultsiadou, E.: The biodiversity of the Mediterranean Sea: estimates, patterns, and threats, PLoS ONE, 5, e11842, doi:10.1371/journal.pone.0011842, 2010.

Danovaro, R. and Pusceddu, A.: Ecomanagement of biodiversity and ecosystem functioning in the Mediterranean Sea: concerns and strategies, Chem. Ecol. 23, 347-360, 2007.

Dauer, D. M.: Biological criteria, environmental health and estuarine macrobenthic community structure, Mar. Pollut. Bull., 26, 249-257, 1993.

Dayton, P. K., Thrush, S. F., Agardy, M. T., and Hofman, R. J.: VIEWPOINT Environmental effects of marine fishing, Aquat. Conserv., 5, 205-232, 1995.

Dernie, K. M., Kaiser, M. J., and Warwick, R. M.: Recovery rates of benthic communities following physical disturbance, J. Anim. Ecol., 72, 1043-1056, 2003.

Diaz, R. J.: Overview of hypoxia around the world, J. Environ. Qual., 30, 275-281, 2001.

Diaz, R. J. and Rosenberg, R.: Marine benthic hypoxia: A review of its ecological effects and the behavioural responses of benthic macrofauna, Oceanogr. Mar. Biol. Ann. Rev., 33, 245-303, 1995.

Diaz, R. J. and Rosenberg, R.: Spreading dead zones and consequences for marine ecosystems, Science, 321, 926-929, 2008.

Erlandsson, J. and Kostylev, V.: Trail following, speed and fractal dimension of movement in a marine prosobranch, Littorina littorea, during a mating and a non-mating season, Mar. Biol., 122, 87-94, 1995.

Fanelli, E., Badalamenti, F., D’Anna, G., Pipitone, C., Riginella, E., and Azzurro, E.: Food partitioning and diet temporal variation in two coexisting sparids, Pagellus erythrinus and Pagellus acarne, J. Fish Biol., 78, 869-900, 2011.

Fedra, K., Ölscher, E. M., Scherübel, C., Stachowitsch, M., and Wurzian, R. S.: On the ecology of a north Adriatic benthic community: distribution, standing crop and composition of the macrobenthos, Mar. Biol., 38, 129-145, 1976.

Folke, C., Carpenter, S., Walker, B., Scheffer, M., Elmqvist, T., Gunderson, L., and Holling, C. S.: Regime shifts, resilience, and biodiversity in ecosystem management, Annu. Rev. Ecol. Evol. Syst., 35, 557-581, 2004.

Glud, R. N. and Blackburn, N.: The effects of chamber size on benthic oxygen uptake measurements: a simulation study, Ophelia, 56, 23-31, 2002.

Gray, J. S., Wu, R. S. S., and Or, Y. Y.: Effects of hypoxia and organic enrichment on the coastal marine environment, Mar. Ecol. Prog. Ser., 238, 249-279, 2002.

Groenewold, S. and Fonds, M.: Effects on benthic scavengers of discards and damaged benthos produced by the beam-trawl fish- ery in the southern North Sea, ICES J. Mar. Sci., 57, 1395-1406, 2000.

Hammer, Ø., Harper, D. A. T., and Ryan, P. D.: PAST: Paleontological statistics software package for education and data analysis, Palaeontol. Electr., 4, 9 pp., 2001.

Hampel, H., Cattrijsse, A., and Mees, J.: Changes in marsh nekton communities along the salinity gradient of the Schelde river, Belgium and the Netherlands, Hydrobiologia, 515, 137-146, 2004.

Haselmair, A., Stachowitsch, M., Zuschin, M., and Riedel, B.: Behaviour and mortality of benthic crustaceans in response to experimentally induced hypoxia and anoxia in situ, Mar. Ecol. Prog. Ser., 414, 195-208, 2010.

Hrs-Brenko, M., Medaković, D., Labura, Ž., and Zahtila, E.: Bivalve recovery after a mass mortality in the autumn of 1989 in the northern Adriatic Sea, Period. Biol., 96, 455-458, 1994.

Jenkins, S. R., Mullen, C., and Brand, A. R.: Predator and scavenger aggregation to discarded by-catch from dredge fisheries: importance of damage level, J. Sea Res., 51, 69-76, 2004.

Jennings, S. and Kaiser, M. J.: The effects of fishing on marine ecosystems, Adv. Mar. Biol., 34, 201-352, 1998.

Jones, H. P. and Schmitz, O. J.: Rapid recovery of damaged ecosystems, PLoS ONE, 4, e5653, doi:10.1371/journal.pone.0005653, 2009.

Justić, D.: Hypoxic conditions in the Northern Adriatic Sea: historical development and ecological significance, in: Tyson, R. V., and Pearson, T. H. (eds.), Modern and Ancient Continental Shelf Anoxia, Geol. Soc. Spec. Publ. 58, London, The Geological Society, London, 95-105, 1991.

Kaiser, M. J. and Spencer, B. E.: The effects of beam-trawl disturbance on infaunal communities in different habitats, J. Anim. Ecol., 65, 348-358, 1996.

Kollmann, H. and Stachowitsch, M.: Long-term changes in the benthos of the Northern Adriatic Sea: a phototransect approach, PSZNI Mar. Ecol., 22, 135-154, 2001.

Koplovitz, G. and McClintock, J. B.: An evaluation of chemical and physical defenses against fish predation in a suite of seagrassassociated ascidians, J. Exp. Mar. Biol. Ecol., 407, 48-53, 2011.

Labropoulou, M. and Eleftheriou, A.: The foraging ecology of two pairs of congeneric demersal fish species: importance of morphological characteristics in prey selection, J. Fish Biol., 50, 324 340, 1997.

Lambert, G. and Lambert, C.: Spicule formation in the solitary ascidian, Herdmania momus, J. Morph., 192, 145-159, 1987.

Lotze, H. K., Coll, M., and Dunne, J. A.: Historical changes in marine resources, food-web structure and ecosystem functioning in the Adriatic Sea, Mediterranean, Ecosyst., 14, 198-222, $2011 \mathrm{a}$.

Lotze, H. K., Coll, M., Magera, A. M., Ward-Paige, C., and Airoldi, L.: Recovery of marine animal populations and ecosystems, Trends Ecol. Evol. 26, 595-605, 2011 b.

Malej, A. and Malačič, V.: Factors affecting bottom layer oxygen depletion in the Gulf of Trieste (Adriatic Sea), Annales, 7, 33 42, 1995

Nixon, S. W.: Coastal marine eutrophication: a definition, social causes, and future concerns, Ophelia, 41, 199-219, 1995.

Norkko, J., Norkko, A., Thrush, S. F., Valanko, S., and Suurkuukka, H.: Conditional responses to increasing scales of disturbance, and potential implications for threshold dynamics in soft-sediment communities, Mar. Ecol. Prog. Ser., 413, 253-266, 2010. 
Officer, C. B., Smayda, T. J., and Mann, R.: Benthic filter feeding: a natural eutrophication control, Mar. Ecol. Prog. Ser., 9, 203-210, 1982.

Ott, J. A. and Fedra, K.: Stabilizing properties of a high-biomass benthic community in a fluctuating ecosystem, Helgoländer Wiss. Meeresunter., 30, 485-494, 1977.

Pallaoro, A., Šantić, M., and Jardas, I.: Feeding habits of common two-banded sea bream, Diplodus vulgaris (Sparidae), in the eastern Adriatic Sea, Cybium, 30, 19-25, 2006.

Pawlik, J. R.: Marine invertebrate chemical defences, Chem. Rev., 93, 1911-1922, 1993.

Pearson, T. H. and Rosenberg, R.: Macrobenthic succession in relation to organic enrichment and pollution of the marine environment, Oceanogr. Mar. Biol. Ann. Rev., 16, 229-331, 1978

Pihl, L., Baden, S. P., Diaz, R. J., and Schaffner, L. C.: Hypoxiainduced structural changes in the diet of bottom-feeding fish and Crustacea, Mar. Biol., 112, 349-361, 1992.

Planes, S., Hertel, O., and Jouvenel, J.-Y.: Analysis of condition and swimming performance in juveniles of white sea bream, Diplodus vulgaris, J. Mar. Biol. Ass. UK, 77, 913-916, 1997.

Pranovi, F., Raicevich, S., Franceschini, G., Farrace, M. G., and Giovanardi, O.: Rapido trawling in the Northern Adriatic Sea: effects on benthic communities in an experimental area, J. Mar. Sci., 57, 517-524, 2000.

Pretterebner, K., Riedel, B., Zuschin, M., and Stachowitsch, M.: Hermit crabs and their symbionts: Reactions to artificially induced anoxia on a sublittoral sediment bottom, J. Exp. Mar. Biol. Ecol., 411, 23-33, 2012.

Richards, W. J. and Lindeman, K. C.: Recruitment dynamics of reef fishes: Planktonic processes, settlement and demersal ecologies, and fishery analysis, Bull. Mar. Sci., 41, 392-410, 1987.

Riedel, B., Stachowitsch M., and Zuschin, M.: Sea anemones and brittle stars: unexpected predatory interactions during induced in situ oxygen crises, Mar. Biol., 153, 1075-1085, 2008b.

Riedel, B., Zuschin, M., Haselmair, A., and Stachowitsch, M.: Oxygen depletion under glass: Behavioural responses of benthic macrofauna to induced anoxia in the Northern Adriatic, J. Exp. Mar. Biol. Ecol., 367, 17-27, 2008a.

Riedel, B., Zuschin, M., and Stachowitsch, M.: Tolerance of benthic macrofauna to hypoxia and anoxia in shallow coastal seas: a realistic scenario, Mar. Ecol. Prog. Ser., 458, 39-52, 2012.

Riemann, B. and Hoffmann, E.: Ecological consequences of dredging and bottom trawling in the Limfjord, Denmark, Mar. Ecol. Prog. Ser., 69, 171-178, 1991.

Rosenberg, R.: Recovery of the littoral fauna in Saltkallefjorden subsequent to discontinued operations of a sulphite pulp mill, Thalassia Jugosl., 7, 341-351, 1971.

Rosenberg, R., Agrenius, S., Hellman, B., Nilsson, H. C., and Norling, K.: Recovery of marine benthic habitats and fauna in a Swedish fjord following improved oxygen conditions, Mar. Ecol. Prog. Ser., 234, 43-53, 2002.

Sawyer, J. A., Zuschin, M., Riedel, B., and Stachowitsch, M.: Predator-prey interactions from in situ time-lapse observations of a sublittoral mussel bed in the Gulf of Trieste (Northern Adriatic), J. Exp. Mar. Biol. Ecol., 371, 10-19, 2009.

Stachowitsch, M.: Mass mortality in the Gulf of Trieste: The course of community destruction, PSZNI Mar. Ecol., 5, 243-264, 1984.
Stachowitsch, M.: Movement, activity pattern, and role of hermit crab population in sublittoral epifaunal community, J. Exp. Mar. Biol. Ecol., 39, 135-150, 1979.

Stachowitsch, M.: The epibiotic and endolithic species associated with the gastropod shells inhabited by the hermit crabs Paguristes oculatus and Paguristes cuanensis, PSZNI Mar. Ecol., 1, 73-101, 1980.

Stachowitsch, M.: The Gulf of Trieste: a sensitive ecosystem, Nova Thalassia, 8, 221-235, 1986.

Stachowitsch, M.: The hermit crab microbiocoenosis: the role of mobile secondary hard bottom elements in a North Adriatic benthic community, in: Biology of Benthic Organisms, Proc. 11th Europ. Mar. Biol. Symp., edited by: Keegan, B. F., O'Ceidigh P., and Boaden, P. J. S., Pergamon Press, London, 549-558, 1977.

Stachowitsch, M.: Anoxia in the Northern Adriatic Sea: Rapid death, slow recovery, Geol. Soc. Spec. Publ., 58, 119-129, 1991.

Stachowitsch, M.: Benthic communities: eutrophication's “memory mode", Sci. Total Environ., 126, 1017-1028, 1992.

Stachowitsch, M. and Avcin, A.: Eutrophication-induced modifications of benthic communities, in: Eutrophication of the Mediterranean Sea: Receiving capacity and monitoring of long-term effects, Unesco Rep. Mar. Sci., 49, 67-80, 1988.

Stachowitsch, M. and Fuchs, A.: Long-term changes in the benthos of the Northern Adriatic Sea, Annales, 7, 7-16, 1995.

Stachowitsch, M., Fanuko, N., and Richter, M.: Mucus aggregates in the Adriatic Sea: An overview of stage and occurrences, PSZNI Mar. Ecol., 11, 327-350, 1990.

Stachowitsch, M., Riedel, B., Zuschin, M., and Machan, R.: Oxygen depletion and benthic mortalities: the first in situ experimental approach to documenting an elusive phenomenon, Limnol. Oceanogr. Methods, 5, 344-352, 2007.

Stachowitsch, M., Riedel, B., and Zuschin, M.: The return of shallow shelf seas as extreme environments: Anoxia and Macrofauna Reactions in the Northern Adriatic Sea, in: Altenbach, A., Bernhard, J., Seckbach, J. (eds.), Anoxia: Evidence for Eukaryote Survival and Paleontological Strategies; Cellular Origins, Life in Extreme Habitats and Astrobiology, Springer Dordrecht Heidelberg London New York, 21, 353-368, 2012.

Stefanon, A. and Boldrin, A.: The oxygen crisis of the northern Adriatic Sea waters in late fall 1977 and its effects on benthic communities, in: World Underwater Federation (CMAS), edietd by: Blanchard, J., Mair, J., and Morrison, I., Proc. 6th Int. Sci., Symp. Natl. Environ. Res. Council, 167-175, 1982.

Stirn, J., Avcin, A., Cencelj, J., Dorer, M., Gomiscek, S., Kveder, S., Malej, A., Meischner, D., Nozina I., Paul, J., and Tusnik, P.: Pollution problems of the Adriatic Sea, an interdisciplinary approach, Rev. Int. Oceanogr. Med., 35/36, 1-78, 1974.

Tuck I. D., Hall, S. J., Robertson, M. R., Armstrong, E., and Basford, D. J.: Effects of physical trawling disturbance in a previously unfished sheltered Scottish sea loch, Mar. Ecol. Prog. Ser., 162, 227-242, 1998.

Turner, R. E., Rabalais, N. N., and Justic, D.: Gulf of Mexico hypoxia: alternate states and a legacy, Environ. Sci. Technol., 42, 2323-2327, 2008.

Van Colen, C., Montserrat, F., Vincx, M., Herman, P. M. J., Ysebaert, T., and Degraer, S.: Long-term divergent tidal flat benthic community recovery following hypoxia-induced mortality, Mar. Pollut. Bull., 60, 178-186, 2010. 
Vaquer-Sunyer, R. and Duarte, C.: Thresholds of hypoxia for marine biodiversity, PNAS, 105, 15452-15457, 2008.

Whitlatch, R. B., Lohrer, A. M., Thrush, S. F. , Pridmore, R. D., Hewitt, J. E., Cummings, V. J., and Zajac, R. N.: Scale-dependent benthic recolonization dynamics: life stage-based dispersal and demographic consequences, Hydrobiologia, 375/376, 217-226, 1998.

Wu, R. S. S.: Hypoxia: from molecular responses to ecosystem responses, Mar. Pollut. Bull., 45, 35-45, 2002.

Wurzian, R. S.: Die Funktion der Räuber der Makro-Epifauna in einer sublitoralen Benthos Gemeinschaft im Golf von Triest, unpublished PhD Thesis, University of Vienna, Vienna, 1982.

Young, C. M.: Distribution and dynamics of an intertidal ascidian pseudopopulation, Bull. Mar. Sci., 45, 288-303, 1989.
Zajac, R. N., Whitlatch, R. B., and Thrush, S. F.: Recolonization and succession in soft-sediment infaunal communities: the spatial scale of controlling factors, Hydrobiologia, 375/376, 227 240, 1998.

Zuschin, M. and Pervesler, P.: Secondary hardground-communities in the Northern Gulf of Trieste, Adriatic Sea, Senckenb. Marit., 28, 53-63, 1996.

Zuschin, M. and Stachowitsch, M.: Epifauna-dominated benthic shelf assemblages: Lessons from the modern Adriatic Sea, Palaios, 24, 211-221, 2009.

Zuschin, M., Stachowitsch, M., Pervesler, P., and Kollmann, H.: Structural features and taphonomic pathways of a high-biomass epifauna in the Northern Gulf of Trieste, Adriatic Sea, Lethaia, 32, 299-317, 1999. 